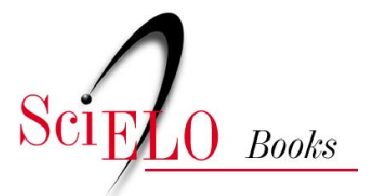

\section{centro edelstein de pesquisas sociais
www.centroedelstein.org.br}

\title{
Segunda parte
}

\author{
Juarez Rubens Brandão Lopes
}

SciELO Books / SciELO Livros / SciELO Libros

LOPES, JRB. Brasil, 1989: um estudo sócio-econômico da indigência e da pobreza [online]. Rio de Janeiro: Centro Edelstein de Pesquisas Sociais, 2008. Segunda parte. pp. 27-45. ISBN: 978-85-9966275-5. Available from SciELO Books $<\underline{\text { http://books. scielo.org }>\text {. }}$

\section{@(1) $(0$}

All the contents of this chapter, except where otherwise noted, is licensed under a Creative Commons Attribution-Non Commercial-ShareAlike 3.0 Unported.

Todo o conteúdo deste capítulo, exceto quando houver ressalva, é publicado sob a licença Creative Commons Atribuição Uso Não Comercial - Partilha nos Mesmos Termos 3.0 Não adaptada.

Todo el contenido de este capítulo, excepto donde se indique lo contrario, está bajo licencia de la licencia Creative Commons Reconocimento-NoComercial-CompartirIgual 3.0 Unported. 


\section{Segunda parte}

O estudo das diferenças regionais, como já dissemos, não visa apenas repetir a análise feita para o Brasil urbano, para as populações urbanas das suas várias regiões. O principal objetivo, é sim, procurar detectar diferenças qualitativas na pobreza das partes mais pobres do país vis-à-vis as mais adiantadas, particularmente quanto à forma de vinculação dos pobres com o mercado de trabalho.

Na maior parte desta análise, utilizarei os cortes usuais de indigência e de pobreza não indigente. Antes, porém, é bom começar por um exame das diferenças regionais nas proporções de pobreza estrutural, pobreza mais recente e pobreza por NBI. Procuro com isso destacar, desde o início, a diferença de qualidade da situação social das duas partes do país.

Os dados pertinentes para esse estudo constam da Tabela 11. O seu exame permite ver com clareza a situação social muito pior e mais dramática das regiões Norte, Centro-Oeste e Nordeste, quando comparadas com a do Sudeste e Sul do país. Esses dados servem também para justificar o recurso freqüente de que lanço mão nessas análises regionais, qual seja o de agrupar os dados do Norte/Centro-Oeste/Nordeste, de um lado, e do Sudeste/Sul, do outro.

\begin{tabular}{|c|c|c|c|c|c|}
\hline & Domicilic & Seg. Situaçōes d & Pobreza: & Năo & \\
\hline Urbanas & Estrutural & Mais Recente & Pob. Por NBI & Scricto Sensu & Total \\
\hline \multicolumn{6}{|l|}{ Norte e Centro/Oeste } \\
\hline N (Milhares) & 547.1 & 639.5 & 203.9 & 1313.8 & 2704.3 \\
\hline$\%$ & 20.23 & 23.65 & 7.54 & 48.58 & 100.00 \\
\hline \multicolumn{6}{|l|}{ Nordeste } \\
\hline $\begin{array}{c}\mathrm{N} \text { (Milhares) } \\
\%\end{array}$ & $\begin{array}{r}1230.5 \\
24.45\end{array}$ & $\begin{array}{r}1463.2 \\
29.08\end{array}$ & $\begin{array}{r}317.8 \\
6.32\end{array}$ & $\begin{array}{r}2019.9 \\
40.15\end{array}$ & $\begin{array}{l}5031.2 \\
100.00\end{array}$ \\
\hline \multicolumn{6}{|l|}{ Sudeste } \\
\hline $\mathrm{N}$ (Milhares) & 1167.6 & 2678.1 & 921.2 & 9169.7 & 13936.5 \\
\hline$\%$ & 8.38 & 19.22 & 6.61 & 65.80 & 100.00 \\
\hline $\mathrm{N}$ (Milhares) & 265.8 & 612.3 & 181.9 & 2891.4 & 3951.4 \\
\hline$\%$ & 6.73 & 15.50 & 4.60 & 73.17 & 100.00 \\
\hline \multicolumn{6}{|l|}{ Brasil } \\
\hline $\mathrm{N}$ (Milhares) & 3210.7 & 5393.1 & 1624.9 & 15394.7 & 25623.4 \\
\hline$\%$ & 12.53 & 21.05 & 6.34 & 60.08 & 100.00 \\
\hline \multicolumn{6}{|l|}{ Ver texto } \\
\hline \multicolumn{6}{|l|}{ FONTE: PNSN 1989} \\
\hline NEPP/UNICAMP 1998. & & & & & \\
\hline
\end{tabular}


Vê-se, assim, que não só as proporções de pobres (indigentes e não indigentes) dessas duas partes do país estão em patamares distintos (como vimos na Tabela 4), mas a própria separação dos pobres em dois componentes - um de pobreza estrutural e outro de pobreza mais recente dá-se em proporções inteiramente distintas nessas duas partes. A relação da pobreza estrutural com a mais recente é 0.86 e 0.84 no Norte/Centro-Oeste e no Nordeste, respectivamente, e 0.44 e 0.43 no Sudeste e no Sul. Também a pobreza por NBI apresenta proporções bem distintas em relação aos não pobres (segundo os dois critérios) nessas duas partes do país: os números correspondentes são agora 0.16 , para as duas regiões mais pobres, e 0,10 e 0,06 para o Sudeste e o $\mathrm{Sul}^{21}$.

A suposição, está claro, é que o componente estrutural da pobreza seja menos mutável do que o conjunto de famílias pobres. Hipótese esta que requer comparações de vários momentos no tempo, e que talvez só possa ser demonstrada a contento através de estudos longitudinais.

De qualquer modo, é difícil escapar-se da impressão de estar a situação social das populações urbanas do Nordeste, do Norte e do vasto interior central do Brasil, num patamar de gravidade, qualitativamente distinto da situação urbana do Sul e do Sudeste.

Voltemos agora para a análise segundo as linhas usuais de indigência e de pobreza não indigente, iniciando, como foi feito para o conjunto do Brasil urbano, com alguns dados gerais.

Esses dados são apresentados separadamente para as duas partes do Brasil urbano nas Tabelas 12 e $13^{22}$.

${ }^{21}$ É claro que a oferta regional de equipamentos urbanos (água, esgoto, vagas na escola), pelo poder público, afeta bastante as variáveis que entram no indicador de necessidades básicas insatisfeitas que foi usado. É claro também que esta oferta diferenciada é um dos fatores responsáveis pelas diferenças, entre as regiões, nas relações entre a pobreza crônica e a recente. Entretanto, tudo isto dito, permanece a importância das diferenças constatadas para a caracterização da pobreza.

${ }^{22}$ Para facilidade de expressão, eu me referirei a estas duas partes, às vezes, como Grande Região Centro-Norte (GRCN) e Grande Região Sul (GRS) e, às vezes, usando expressões que se refiram ao relativo atraso econômico da primeira grande região em relação à segunda ("Brasil mais atrasado", "parte mais atrasada do país..."), já que essa é principal dimensão segundo a qual as duas partes diferem entre si.
Tabela 12

Distribuiçăo Percentual de Domicilios, Pessoas, Crianças e de Chefes Pretos e Pardos, Segundo Niveis de Pobreza, Grande Região Centro-Oeste (GRCN), 1989

\begin{tabular}{|c|c|c|c|c|c|c|}
\hline \multirow[t]{2}{*}{ Norte/Centro-Oeste } & \multicolumn{3}{|c|}{ Niveis de Pobreza } & \multicolumn{2}{|c|}{$\mathrm{P}$} & \multirow{2}{*}{$\begin{array}{c}\text { Total } \\
\text { (milhares) }\end{array}$} \\
\hline & 1 & $\mathrm{Pn}$ & NP & $1+P_{n}$ & $\%$ & \\
\hline Domicilios & 13.43 & 30.17 & 56.40 & 43.60 & 100.00 & 2725.4 \\
\hline Pessoas & 16.24 & 33.13 & 50.63 & 49.37 & 100.00 & 12222.8 \\
\hline Crianças 0.3 anos & 22.98 & 34.31 & 42.72 & 57.28 & 100.00 & 1206.3 \\
\hline Chefes Pretos e Pardos & 16.11 & 35.03 & 48.86 & 51.14 & 100.00 & 1651.9 \\
\hline \multirow[t]{2}{*}{ Nordeste } & \multicolumn{3}{|c|}{ Niveis de Pobreza } & \multicolumn{2}{|c|}{$\mathrm{P}$} & Total \\
\hline & 1 & $\mathrm{Pn}$ & $\mathrm{NP}$ & $1+P n$ & $\%$ & (milhares) \\
\hline Domicilios & 22.97 & 30.55 & 46.48 & 53.52 & 100.00 & 5048.3 \\
\hline Pessoas & 29.43 & 29.68 & 40.89 & 59.11 & 100.00 & 23307.1 \\
\hline Crianças $0-3$ anos & 40.81 & 27.55 & 31.64 & 68.36 & 100.00 & 2203.2 \\
\hline Chefes Pretos e Pardos & 25.83 & 32.02 & 42.14 & 57.86 & 100.00 & 3853.6 \\
\hline GRCN: Norte/ & \multicolumn{3}{|c|}{ Niveis de Pobreza } & \multicolumn{2}{|r|}{ sove } & Total \\
\hline Centro-Oeste/Nordeste & 1 & $\mathrm{Pn}$ & $\mathrm{NP}$ & $1+P_{n}$ & $\%$ & (milhares) \\
\hline Domicilios & 19.62 & 30.42 & 49.96 & 50.04 & 100.00 & 7773.7 \\
\hline Pessoas & 24.89 & 30.87 & 44.24 & 55.76 & 100.00 & 35529.9 \\
\hline Crianças $0-3$ anos & 34.50 & 29.94 & 35.56 & 64.44 & 100.00 & 3409.5 \\
\hline Chefes Pretos e Pardos & 22.92 & 32.92 & 44.16 & 55.84 & 100.00 & 5505.6 \\
\hline
\end{tabular}

\section{FONTE: PNSN, 1989}

NEPP/UNICAMP, 1998.

Estes dados não necessitam muitos comentários. Servem para balizar as análises que se seguem. Basta por ora assinalar alguns poucos pontos. Em particular, as informações mais graves são que quase duas de cada três crianças urbanas da vasta Grande Região Centro-Norte (regiões Norte, Centro-Oeste e Nordeste), são pobres e que cerca de um em cada cinco domicílios, é indigente (as estatísticas correspondentes para as regiões Sudeste e Sul são pouco mais de duas em cinco crianças urbanas são pobres e apenas um domicílio em cada 14 é indigente, respectivamente).

$\mathrm{Na}$ grande região mais atrasada do país, tendo menos de um terço dos domicílios urbanos totais do país e 54 por cento dos domicílios indigentes, estão 58 por cento ou seja quase três de cada cinco crianças indigentes de Brasil urbano.

Outro dado importante, que decorre dessa distribuição desigual de domicílios e pessoas, nos vários níveis de pobreza, pelas duas grandes regiões, diz respeito ao tamanho dos domicílios. A Grande Região CentroNorte, como seria de se esperar, possui domicílios sensivelmente maiores do que a Grande Região Sul: de 4,6 pessoas comparadas com 3.8. Esta diferença está relacionada tanto à fertilidade mais alta naquela região, como 
também à maior proporção nela existente de domicílios com mais de uma família. Entretanto, ao analisarmos o tamanho do domicílio segundo diferentes níveis de pobreza, encontramos um fato não tão óbvio. Verificamos que a principal diferença está nos domicílios pobres das duas grandes regiões, particularmente nos indigentes (para os quais se verifica uma diferença de quase uma pessoa e meia, pois os tamanhos médios dos domicílios para as duas grandes regiões são 5,8 e 4,4), enquanto a diferença para os não pobres é pequena (4,0 e 3,7 respectivamente). Para os nossos objetivos, deve-se salientar, mais do que a uniformização que se verifica nesse aspecto nas camadas mais altas do país, o que isso pode significar em termos de diferenças qualitativas na pobreza e na indigência entre as duas partes do Brasil. Não só as proporções de pobres e de indigentes no Brasil atrasado são muito mais altas, mas o que significa ser pobre ou ser indigente, num e noutro Brasil é muito diferente.

\section{Tabela 13}

Distribuição Percentual de Domicílios, Pessoas, Crianças e de Chefes Pretos e Pardos, Segundo Niveis de Pobreza, Grande Regiăo Sul (GRS), 1989.

\begin{tabular}{|c|c|c|c|c|c|c|}
\hline \multirow[t]{2}{*}{ Sudeste } & \multicolumn{3}{|c|}{ Niveis de Pobreza } & \multicolumn{2}{|c|}{$\mathrm{P}$} & \multirow{2}{*}{$\begin{array}{c}\text { Total } \\
\text { (milhares) }\end{array}$} \\
\hline & 1 & $\mathrm{Pn}$ & $\mathrm{NP}$ & $I+P n$ & $\%$ & \\
\hline Domicilios & 7.49 & 20.07 & 72.43 & 27.57 & 100.00 & 13949.6 \\
\hline Pessoas & 8.41 & 23.07 & 68.52 & 31.48 & 100.00 & 53988.6 \\
\hline Crianças $0-3$ anos & 16.87 & 28.82 & 54.30 & 45.70 & 100.00 & 4259.8 \\
\hline Chefes Pretos e Pardos & 13.42 & 30.76 & 55.81 & 44.19 & 100.00 & 4380.0 \\
\hline \multirow[t]{2}{*}{ Sul } & \multicolumn{3}{|c|}{ Niveis de Pobreza } & \multicolumn{2}{|c|}{$\mathrm{P}$} & Total \\
\hline & 1 & $\mathrm{Pn}$ & $\mathrm{NP}$ & $1+P n$ & $\%$ & (milhares) \\
\hline Domicilios & 6.61 & 15.60 & 77.78 & 22.22 & 100.00 & 3963.2 \\
\hline Pessoas & 7.81 & 17.36 & 74.83 & 25.17 & 100.00 & 14964.4 \\
\hline Crianças $0-3$ anos & 11.56 & 22.21 & 66.22 & 33.78 & 100.00 & 1209.9 \\
\hline Chefes Pretos e Pardos & 14.13 & 22.83 & 63.04 & 36.96 & 100.00 & 519.0 \\
\hline \multirow[t]{2}{*}{ GRS: Sudeste/Sul } & \multicolumn{3}{|c|}{ Niveis de Pobreza } & \multicolumn{2}{|c|}{$\mathrm{P}$} & Total \\
\hline & 1 & $\mathrm{Pn}$ & NP & $1+P n$ & $\%$ & (milhares) \\
\hline Domicilios & 7.30 & 19.09 & 73.62 & 26.38 & 100.00 & 17912.8 \\
\hline Pessoas & 8.28 & 21.83 & 69.89 & 30.11 & 100.00 & 68953.0 \\
\hline Crianças 0 - 3 anos & 15.70 & 27.36 & 56.94 & 43.06 & 100.00 & 5469.7 \\
\hline Chefes Pretos e Pardos & 13.50 & 29.92 & 56.58 & 43.42 & 100.00 & 4898.9 \\
\hline
\end{tabular}

NEPP/UNICAMP, 1998.

Passo, agora, à análise da estrutura familiar dos domicílios na sua relação com a pobreza, nas duas grandes regiões (Tabela 14).
Os dados da Tabela 14 revelam a composição dos domicílios pobres urbanos segundo a sua estrutura familiar. Nas duas grandes regiões a maioria, cerca de 52 e 58 por cento na Grande Região Centro-Norte e na Grande Região Sul respectivamente, é constituída de famílias de casais, jovens e de meia-idade, com os seus filhos, incluindo às vezes alguma outra pessoa. 
Tabela 14

Estrutura Familiar dos Domicílios, Grandes Regiōes do Brasil (GRCN e GRS), 1989 GRCN: Norte. Centro-Oeste e Nordeste

\begin{tabular}{|c|c|c|c|c|c|}
\hline \multirow{2}{*}{$\begin{array}{l}\text { Estruturas } \\
\text { Familiares (1) }\end{array}$} & \multicolumn{4}{|c|}{ Domicilios } & \multirow{2}{*}{$\begin{array}{l}\text { Probabilidade } \\
\text { De ser Pobre }\end{array}$} \\
\hline & Pobres & $\%$ & Total & $\%$ & \\
\hline 1 & 14554 & 0.37 & 167977 & 2.16 & 8.66 \\
\hline $\mathrm{co}$ & 65362 & 1.68 & 287081 & 3.69 & 22.77 \\
\hline C1 & 889109 & 22.86 & 1698828 & 21.85 & $52.34\left(\left(^{\circ}\right)\right.$ \\
\hline $\mathrm{C} 2$ & 1141055 & 29.33 & 2283473 & 29.37 & 49.97 \\
\hline ID1 & 395570 & 10.17 & 742423 & 9.55 & $53.28\left(\left(^{*}\right)\right.$ \\
\hline 1D2 & 263756 & 6.78 & 443762 & 5.71 & $59.44\left(^{*}\right)$ \\
\hline Outr & 138706 & 3.57 & 475143 & 6.11 & 29.19 \\
\hline Pluri & 448935 & 11.54 & 786705 & 10.12 & 57.07 \\
\hline M1 & 141868 & 3.65 & 235385 & 3.03 & $60.27\left(^{*}\right)$ \\
\hline M2 & 391283 & 10.06 & 652928 & 8.40 & $59.93\left(^{*}\right)$ \\
\hline Total & 3890198 & 100.00 & 7773705 & 100.00 & 50.04 \\
\hline \multicolumn{6}{|c|}{ GRS: Sudeste e Sul } \\
\hline Estruturas & \multicolumn{4}{|c|}{ Domicílios } & Probabilidade \\
\hline Familiares (1) & Pobres & $\%$ & Total & $\%$ & De ser Pobre \\
\hline$T$ & 5674 & 0.12 & 299731 & 1.67 & 1.89 \\
\hline $\mathrm{co}$ & 69931 & 1.48 & 667202 & 3.72 & 10.48 \\
\hline C1 & 1184552 & 25.06 & 3750575 & 20.94 & $31.58\left(^{*}\right)$ \\
\hline $\mathrm{C} 2$ & 1547894 & 32.75 & 6189169 & 34.55 & 25.01 \\
\hline ID1 & 289673 & 6.13 & 1338487 & 7.47 & 21.64 \\
\hline ID2 & 274160 & 5.80 & 1035466 & 5.78 & 26.48()$\left.^{*}\right)$ \\
\hline Outr & 240729 & 5.09 & 1466926 & 8.19 & 16.41 \\
\hline Pluri & 419621 & 8.88 & 1378955 & 7.70 & $30.43(")$ \\
\hline M1 & 215097 & 4.55 & 364475 & 2.03 & $59.02\left(\left(^{*}\right)\right.$ \\
\hline M2 & 478802 & 10.13 & 1421846 & 7.94 & $33.67\left(^{*}\right)$ \\
\hline Total & 4726133 & 100.00 & 17912832 & 100.00 & 26.38 \\
\hline
\end{tabular}

\section{FONTE: PNSN, 1989}

NEPPJUNICAMP, 1998
Comparando-se nas duas grandes regiões a proporção de cada tipo de estrutura entre os pobres urbanos, é marcante outra diferença. Para caracterizá-la, chamemos a atenção para dois fatos, aparentemente não relacionados. O primeiro é a bem maior porcentagem de domicílios plurifamiliares e de famílias idosas em que permanecem ainda filhos adultos, existente nas populações pobres urbanas da região mais atrasada do país (a Centro-Norte). Aí estes casos constituem 22 por cento dos domicílios pobres urbanos, comparados com 15 por cento na Grande Região Sul. O outro fato é a proporção sensivelmente maior entre os pobres urbanos do Sudeste e Sul, de famílias de mulheres jovens, sem cônjuge, com filhos menores.

Note-se, primeiro, que os dois tipos de estrutura familiar que são, proporcionalmente, mais freqüentes entre os pobres urbanos na grande região mais atrasada do país, são, na realidade, variantes de uma mesma situação. Aquela que junta no mesmo domicílio pessoas de duas gerações, filhos ou filhas adultas, com os seus pais (um deles ou o casal). Quando estes filhos(as) adultos não têm, por sua vez, filhos consigo, temos o caso do tipo ID1; quando os têm, dá-se o caso dos domicílios pluri-familiares ${ }^{23}$. Este fato, por conseguinte, relaciona-se com a menor proporção entre os pobres da grande região atrasada, do que no Sudeste e Sul, de mulheres jovens, sem cônjuge e com filhos (caso que na Grande Região Centro-Norte estaria, com bastante freqüência, dentro das unidades familiares compostas do tipo ID1 e em domicílios pluri-familiares $)^{24}$. Note-se, finalmente, que desta maneira, nas unidades familiares compostas, seja pela permanência de padrões tradicionais ou por uma estratégia deliberada de sobrevivência, procura-se socializar condições de vida, proteger contra o desemprego e contra dificuldades especiais advindas da idade avançada de membros da família. Examinando-se as probabilidades de ser pobre (Gráfico 2), pode-se perceber como existem diferenciais mais pronunciados na Grande Região Sul do que na Centro-Norte (note-se por exemplo a curva formada pela

${ }^{23}$ Um exame dos domicílios plurifamiliares mostrou que os casos mais freqüentes são aqueles em que o(a) chefe(a) da família secundária é filho(a) ou pai do chefe do domicílio (chefe da família principal).

${ }^{24}$ Uma observação: O tamanho médio maior do domicílio pobre urbano na Grande Região Centro Norte, assinalado acima, deve relacionar-se com a maior prevalência nessa região dessas unidades compostas. 
seqüência de probabilidades dos tipos C1, C2, 101 e 102, ou pelo par M1 e M2). Isso deve resultar, em parte, da já mencionada maior proporção de domicílios pluri-familiares entre os pobres urbanos da região atrasada. Se as famílias componentes fossem consideradas separadamente, acentuar-se-iam as probabilidades de ser pobre dos tipos C1 e M1 (casais e mulheres sem cônjuge, nos dois casos jovens e com filhos pequenos). A Tabela 15 fornece-nos dados para os diferentes níveis de pobreza, sobre as duas grandes regiões, dados esses referentes a algumas características físicas e sanitárias das habitações, bem como a presença de livros e a posse de aparelho de televisão no domicílio.

Sem analisá-las em detalhe, apontemos apenas as grandes diferenças de condições de vida das populações indigentes e não indigentes, entre as duas Grandes Regiões. As proporções de características más na Grande Região Centro-Norte são quase sempre mais do que o dobro das da Grande Região Sul e freqüentemente muito mais do que o dobro, como é o caso das características sanitárias das populações pobres não indigentes.
Tabela 15

Caracteristicas Fisicas da Habitação, suas Condições Sanitárias e Bens que Possuem,

Segundo Niveis de Pobreza, Grandes Regiōes Urbanas (GRCN e GRS), 1989

\begin{tabular}{|c|c|c|c|c|}
\hline \multicolumn{5}{|l|}{ GRCN: Norte/ Centro-Oeste/Nordeste } \\
\hline \multirow[t]{2}{*}{ Caracteristicas Selecionadas } & \multicolumn{3}{|c|}{ Niveis de Pobreza } & \multirow[t]{2}{*}{.Total } \\
\hline & 1 & $\mathrm{Pn}$ & NP & \\
\hline 1. Paredes de Taipa, Madeira & 16.01 & 8.96 & 1.76 & 6.76 \\
\hline \multicolumn{5}{|l|}{ Aproveitada ou ' Outro' Material } \\
\hline 2. Piso de Terra ou de Madeira & 23.06 & 10.28 & 2.41 & 8.88 \\
\hline \multicolumn{5}{|l|}{ Aproveitada } \\
\hline 3. Sem Canalização Interna & 58.37 & 40.05 & 13.89 & 31.84 \\
\hline \multicolumn{5}{|l|}{ De Água } \\
\hline 4. Não tem Vaso Sanitário ou & 64.36 & 42.89 & 13.15 & 32.30 \\
\hline \multicolumn{5}{|l|}{ Esse não é de Cerámica } \\
\hline 5. Não tem T.V. & 58.67 & 40.30 & 15.16 & 31.39 \\
\hline 6. Não tem Livros & 73.69 & 59.93 & 30.42 & 47.94 \\
\hline
\end{tabular}

GRS: Sudeste/Sul

\begin{tabular}{lcccc}
\hline 1. Paredes de Taipa, Madeira & 7.71 & 4.32 & 0.74 & 1.93 \\
$\begin{array}{l}\text { Aproveitada ou ' Outro' Material } \\
\text { 2. Piso de Terra ou de Madeira }\end{array}$ & 9.17 & 3.21 & 0.58 & 1.71 \\
$\begin{array}{l}\text { Aproveitada } \\
\text { 3. Sem Canalizaçăo Interna }\end{array}$ & 31.31 & 10.95 & 3.13 & 6.68 \\
$\begin{array}{l}\text { De Agua } \\
\text { 4. Não tem Vaso Sanitário ou }\end{array}$ & 30.47 & 10.50 & 3.01 & 6.44 \\
$\begin{array}{l}\text { Esse não é de Cerâmica } \\
\text { 5. Não tem T.V. }\end{array}$ & 38.53 & 19.38 & 6.92 & 11.60 \\
6. Não tem Livros & 58.55 & 43.57 & 23.56 & 29.94 \\
\hline
\end{tabular}

FONTE: PNSN, 1989

NEPP/UNICAMP, 1998

Como foi feito no estudo para o Brasil urbano total, passo, agora, a examinar alguns condicionantes demográficos e sócio-econômicos da pobreza urbana. Como já disse, ao invés de repetir a análise feita para o 
conjunto do país, limito-me nesta parte a apontar as principais diferenças regionais e, quando possível, o seu significado mais amplo. Começo pela Tabela 16, com os dados da estrutura demográfica dos domicílios.

Probab. de ser pobre segundo estruturas familiares, grandes regiōes urbanas

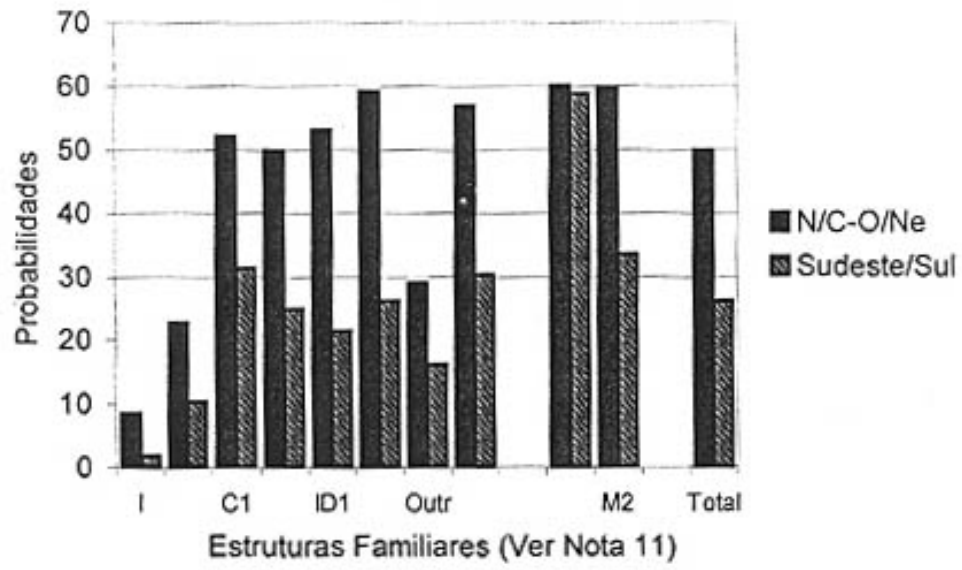

O que há a notar nos dados dessa tabela, quanto a diferenciais regionais, confirma a análise feita, quando do exame dos dados das Tabelas 12 e 13. Isto é, a enorme desvantagem, embutida na estrutura de idades, das populações indigentes da região mais atrasada, a Centro-Norte, comparada com as indigentes da Sul. Atente-se, também, para o muito maior tamanho médio do domicilio indigente daquela grande região, e para a presença nela de uma bem menor proporção de chefes de domicílio mulheres, - fatos, como já apontamos, certamente relacionados com a maior prevalência aí de unidades compostas, caracterizadas como o fizemos na discussão dos dados sobre estrutura familiar (Tabela 14). Naquele passo, sugerimos ser a estruturação de domicílios daquelas formas, 'defesas' contra a insegurança representada pela falta de empregos e de previdência social ${ }^{25}$. Pode-se especular o que tais arranjos familiares realmente significam no sentido de socialização de condições de vida, e como isso repercute nas estatísticas. Possivelmente o consumo familiar nessas unidades compostas, já em nível muito baixo, se uniformiza num nível ainda inferior, e as taxas de desemprego diminuem (relativamente ao que seriam), com um possível aumento das taxas de inatividade.

\footnotetext{
${ }^{25}$ Expliquemos a referência à falta de previdência social. Quero referir-me à situação concreta, onde a falta de empregos em empresas, reduz os indivíduos a empregos sem garantias legais (sem carteira de trabalho e sempre nessa situação não há contribuição à previdência) ou ao trabalho por conta própria, com ganhos muito baixos, tornando irreal a possibilidade legal de contribuição voluntária à previdência.
} 
Tabela 16

Vários Indicadores da Composição Etária e Por Sexo do Domicilio, Segundo Niveis de Pobreza, Grandes Regiōes Urbanas (GRCN e GRS), 1989.

\begin{tabular}{|c|c|c|c|c|}
\hline \multicolumn{5}{|l|}{ GRCN: Norte/ Centro-Oeste/ Nordeste } \\
\hline \multirow{2}{*}{$\begin{array}{c}\text { Indicadores da Composiçăa } \\
\text { Etaria e por Sexo }\end{array}$} & \multicolumn{3}{|c|}{ Niveis de Pobreza } & \multirow[t]{2}{*}{ Total } \\
\hline & $T$ & $\mathrm{Pn}$ & NP & \\
\hline \multicolumn{5}{|l|}{ Medias de Pessoas p/ Domicllio } \\
\hline (1) 0.9 & 2.100 & 1.168 & 0.779 & 1.157 \\
\hline (2) $10 \cdot 17$ & 1.324 & 0.927 & 0.605 & 0.844 \\
\hline (3) 18.59 & 2.059 & 2.082 & 2.228 & 2.151 \\
\hline (4) $60+$ & 0.312 & 0.440 & 0.324 & 0.357 \\
\hline Total & 5.797 & 4.638 & 4.048 & 4.571 \\
\hline$\%$ Chefes Mulheres & 25.60 & 26.46 & 20.26 & 23.20 \\
\hline \multicolumn{5}{|l|}{ Pessoas em Idade nåo Produtiva } \\
\hline Por Pessoa em Idade Produtiva (") & 1.814 & 1.217 & 0.767 & 1.096 \\
\hline \multicolumn{5}{|l|}{ GRS: Sudeste/Sul } \\
\hline \multicolumn{5}{|l|}{ Médias de Pessoas p/ Domicllio } \\
\hline (1) 0.9 & 1.539 & 1.163 & 0.645 & 0.809 \\
\hline (2) $10-17$ & 0.775 & 0.927 & 0.535 & 0.627 \\
\hline (3) $18 \cdot 59$ & 1.818 & 2.027 & 2.134 & 2.091 \\
\hline (4) $60+$ & 0.228 & 0.284 & 0.303 & 0.294 \\
\hline Total & 4.367 & 4.404 & 3.654 & 3.849 \\
\hline$\%$ Chefes Mulheres & 35.68 & 22.27 & 18.57 & 20.52 \\
\hline \multicolumn{5}{|l|}{ Pessoas em Idade nâo Produtiva } \\
\hline Por Pessoa em Idade Produtiva (") & 1.399 & 1.171 & 0.695 & 0.828 \\
\hline
\end{tabular}

$($ () $[(1)+(2)+(4))(3)$

FONTE: PNSN, 1989

Algumas dessas coisas podem ser vislumbradas nas tabelas finais dessa nossa análise, onde focalizo as diferenças regionais, quanto as características do chefe do domicílio e de seu trabalho (Tabela 17 e 18), e quanto ao trabalho e renda dos moradores do domicílio em conjunto (Tabela 19 e 20), sempre segundo níveis de pobreza.

Como exemplos chamo a atenção para o altíssimo grau de analfabetismo dos chefes de domicílios indigentes no Nordeste (59\%), não acompanhado de perto pela taxa de qualquer outra região; a alta proporção de ocupações agrícolas (17\%) dos chefes indigentes do Sudeste (num nível muito mais alto de qualquer outra região); e a proporção de aposentados e pensionistas nos domicílios indigentes, entre as pessoas com 40 anos e mais, especialmente alta na região Sul (47\%) e baixa no Nordeste (30\%).

Tabela 17

Caracteristicas do Chefe do Domicilio, Segundo Niveis de Pobreza, Grande Região Urbana GRNC, 1989

\begin{tabular}{|c|c|c|c|c|}
\hline \multirow{2}{*}{$\begin{array}{c}\text { Norte e Centro-Oeste } \\
\text { Caracteristica Selecionada do Chefe }\end{array}$} & \multicolumn{3}{|c|}{ Nivel de Pobreza } & \multirow[t]{2}{*}{ Total } \\
\hline & 1 & $P_{n}$ & $\mathrm{NP}$ & \\
\hline$\%$ Analfabetos & 36.20 & 23.54 & 7.30 & 16.80 \\
\hline$\%$ Ocupados & 68.51 & 81.48 & 88.89 & 83.92 \\
\hline \multicolumn{5}{|l|}{ Distrib. Seg. Pos. Ocupação } \\
\hline Empregados & 56.95 & 59.79 & 57.58 & 58.16 \\
\hline Ocupaçóes Agricolas & 7.72 & 4.35 & 2.40 & 3.55 \\
\hline Conta Propria & 34.28 & 34.45 & 30.74 & 32.21 \\
\hline Empregador e Nåo Remunerado & 1.05 & 1.41 & 9.29 & 6.08 \\
\hline \multicolumn{5}{|l|}{$\%$ Chefes Empregados s/ Carteira } \\
\hline De Trabalho & 52.46 & 37.90 & 32.45 & 36.39 \\
\hline \multicolumn{5}{|l|}{ \% Conta Própria, Empregador e Năo } \\
\hline Remunerado. Não Contribuinte. & 85.99 & 82.12 & 55.06 & 65.61 \\
\hline \multicolumn{5}{|l|}{ \% Chefe que Procurou Trabalho } \\
\hline Ültimos 12 Meses $\left(\left(^{*}\right)\right.$ & 27.02 & 19.18 & 12.50 & 16.46 \\
\hline Nordeste & \multicolumn{3}{|c|}{ Nivel de Pobreza } & Total \\
\hline Caracteristica Selecionada do Chefe & 1 & $P_{n}$ & NP & \\
\hline$\%$ Analfabetos & 58.65 & 44.64 & 17.32 & 35.16 \\
\hline \% Ocupados & 70.40 & 70.26 & 79.96 & 74.80 \\
\hline \multicolumn{5}{|l|}{ Distrib. Seg. Pos. Ocupação } \\
\hline Empregados & 54.91 & 52.72 & 51.79 & 52.74 \\
\hline Ocupaç১es Agricolas & 6.99 & 2.40 & 1.38 & 2.89 \\
\hline Conta Própria & 37.25 & 42.89 & 39.35 & 39.91 \\
\hline Empregador e Não Remunerado & 0.85 & 1.99 & 7.48 & 4.46 \\
\hline \multicolumn{5}{|l|}{$\%$ Chefes Empregados s/ Carteira } \\
\hline De Trabalho & 55.59 & 46.86 & 29.74 & 40.69 \\
\hline \multicolumn{5}{|l|}{ \% Conta Própria, Empregador e Nåo } \\
\hline Remunerado. Não Contribuinte. & 87.13 & 85.87 & 59.03 & 72.05 \\
\hline \multicolumn{5}{|l|}{$\%$ Chefe que Procurou Trabalho } \\
\hline Ülttimos 12 Meses (") & 25.09 & 16.69 & 8.81 & 14.95 \\
\hline
\end{tabular}

(") Inclusive os que procuraram trabalho nas ültimas 4 semanas

FONTE: PNSN, 1989

NEDONINICAMP 1998 
Nos domicílios pobres não indigentes notam-se também, para as mesmas regiões, diferenças, no geral semelhantes às dos domicílios indigentes, num nível porém menos saliente: analfabetismo mais alto do chefe no Nordeste (45\%); taxa mais alta de ocupações agrícolas de chefes no Sudeste $(6 \%)$, agora acompanhada por taxa igualmente alta dos chefes do Sul (7\%); proporção de pessoas com 40anos e mais aposentadas ou pensionistas, especialmente alta no Sul (50\%), agora seguida por taxa também alta no Nordeste (49\%).

Quando se passa, portanto, da análise das proporções globais de indigentes e pobres não indigentes, do desdobramento da pobreza nos seus componentes crônico e recente, e do estudo das características demográficas e de estruturas familiares, para aquelas referentes ao trabalho e à renda, do chefe do domicílio e do conjunto de moradores, encontra-se maior heterogeneidade regional e a impressão de uma divisão relativamente nítida do país em duas grandes regiões se desfaz.

O contraste que permanece, agora, de forma clara é o que existe entre duas regiões, a Nordeste, de um lado, e a Sudeste do outro (que são, aliás, as duas principais partes, em número de domicílios e de pessoas, dos dois agregados mais amplos, as grandes regiões que analisei antes).

Contrastando essas duas regiões, juntam-se às grandes diferenças nas proporções de indigentes e de pobres não indigentes (e nas proporções dos componentes 'estrutural' e 'recente' da pobreza), diferenças qualitativas referentes aos tipos de indigentes e de pobres não indigentes que existem numa e noutra.

Vêem-se estas diferenças no que diz respeito a características físicas e sanitárias dos domicílios, e a seus contatos com o mundo mais amplo; também pode-se apreciá-las no referente a características demográficas e estruturas familiares.

Podemos acrescentar, agora, contrastes - no confronto entre os indigentes e pobres de uma e de outra dessas duas regiões - que dizem respeito aos seus vínculos com os mercados de trabalho. No Nordeste, estas populações pobres, e particularmente as indigentes, estariam mais segregadas, num mercado de trabalho 'pobre', segmentado mais nitidamente.
Tabela 18

Caracteristicas do Chefe do Domicílio, Segundo Niveis de Pobreza, Grande Região Urbana GRS, 1989

\begin{tabular}{|c|c|c|c|c|}
\hline \multirow{2}{*}{$\begin{array}{l}\text { Sudeste } \\
\text { Caracteristica Selecionada do Chefe }\end{array}$} & \multicolumn{3}{|c|}{ Nivel de Pobreza } & \multirow[t]{2}{*}{ Total } \\
\hline & $T$ & Pn & NP & \\
\hline$\%$ Analfabetos & 34.09 & 19.94 & 6.65 & 11.37 \\
\hline$\%$ Ocupados & 65.50 & 81.61 & 81.01 & 79.97 \\
\hline \multicolumn{5}{|l|}{ Distrib. Seg. Pos. Ocupaçåo } \\
\hline Empregados & 49.80 & 69.58 & 67.01 & 66.48 \\
\hline Ocupaçð̄es Agricolas & 17.38 & 6.13 & 0.57 & 2.74 \\
\hline Conta Própria & 29.98 & 20.12 & 24.86 & 24.21 \\
\hline Empregador e Nåo Remunerado & 2.83 & 4.17 & 7.55 & 6.57 \\
\hline \multicolumn{5}{|l|}{ \% Chefes Empregados s/ Carteira } \\
\hline De Trabalho & 49.54 & 25.15 & 18.45 & 21.77 \\
\hline \multicolumn{5}{|l|}{ \% Conta Própria, Empregador e Não } \\
\hline Remunerado. Não Contribuinte. & 82.04 & 59.60 & 41.54 & 46.02 \\
\hline \multicolumn{5}{|l|}{ \% Chefe que Procurou Trabalho } \\
\hline Últimos 12 Meses (*) & 26.53 & 26.45 & 12.05 & 16.03 \\
\hline Sul & \multicolumn{3}{|c|}{ Nivel de Pobreza } & Total \\
\hline Característica Selecionada do Chefe & 1 & $P_{n}$ & NP & \\
\hline$\%$ Analfabetos & 39.17 & 20.58 & 6.10 & 10.55 \\
\hline$\%$ Ocupados & 46.47 & 70.12 & 82.30 & 78.03 \\
\hline \multicolumn{5}{|l|}{ Distrib. Seg. Pos. Ocupaçåo } \\
\hline Empregados & 66.33 & 69.27 & 58.77 & 60.54 \\
\hline Ocupaçóes Agricolas & 4.05 & 7.37 & 1.32 & 2.28 \\
\hline Conta Própria & 29.62 & 22.21 & 29.82 & 28.75 \\
\hline Empregador e Năo Remunerado & 0.00 & 1.14 & 10.08 & 8.43 \\
\hline \multicolumn{5}{|l|}{$\%$ Chefes Empregados s/ Carteira } \\
\hline De Trabalho & 60.45 & 33.78 & 16.74 & 21.60 \\
\hline \multicolumn{5}{|l|}{ \% Conta Própria, Empregador e Não } \\
\hline Remunerado. Nǎo Contribuinte. & 86.65 & 66.20 & 40.31 & 44.05 \\
\hline \multicolumn{5}{|l|}{$\%$ Chefe que Procurou Trabalho } \\
\hline Últimos 12 Meses (") & 25.96 & 25.77 & 11.24 & 14.48 \\
\hline
\end{tabular}


Examinando-se as estatísticas referentes aos chefes dos domicílios indigentes e pobres não indigentes urbanos (Tabela 17 e 18), destacam-se as porcentagens bem maiores no Nordeste do que no Sudeste, em qualquer dos dois níveis de pobreza, de trabalhadores por conta própria (contrabalançadas no Sudeste por maiores proporções de empregados, inclusive de trabalhadores na agricultura). Que espécie de conta própria é este trabalhador nordestino pode ser visualizado pelas muito mais altas porcentagens naquela região (sempre comparando às mesmas estatísticas para o Sudeste) de chefes analfabetos e de ausência entre eles de emprego com carteira de trabalho e/ou contribuição à previdência.
TABELT 19

Trabalho e Renda dos Membros do Domicilio, Segundo Niveis de Pobreza, Grande Regiāo Urbana GRNC

1989.

\begin{tabular}{|c|c|c|c|c|}
\hline \multirow{3}{*}{$\begin{array}{l}\text { Norte e Centro-Oeste } \\
\text { Trabalho e Renda dos Moradores } \\
\text { Do Domicllio }\end{array}$} & \multicolumn{3}{|c|}{ Nivel de Pobreza } & \multirow[t]{3}{*}{ Total } \\
\hline & \multirow[b]{2}{*}{$T$} & \multirow[b]{2}{*}{$\mathrm{Pn}$} & \multirow[b]{2}{*}{ NP } & \\
\hline & & & & \\
\hline$\%$ de Domicilios com 0 Ocupados & 16.90 & 7.17 & 2.53 & 5.86 \\
\hline Pessoas por Ocupado no Domicilio & 4.02 & 2.66 & 2.12 & 2.48 \\
\hline \multicolumn{5}{|l|}{ Distribuiçâo dos Domicilios } \\
\hline \multicolumn{5}{|l|}{ Segundo o Tipo de Renda } \\
\hline So Renda de Trabalho & 47.69 & 47.55 & 47.42 & 47.50 \\
\hline S6 Outras Rendas (") & 18.62 & 7.52 & 2.93 & 6.41 \\
\hline Renda de Trabalho e Outras Rendas & 33.68 & 44.94 & 49.64 & 46.10 \\
\hline \multicolumn{5}{|l|}{$\%$ de Pessoas d 10 anos e + } \\
\hline Desocupadas & 9.86 & 5.55 & 3.28 & 4.93 \\
\hline \multicolumn{5}{|l|}{$\%$ de Chefes com mais de 40 Anos } \\
\hline Aposentados ou Pensionistas & 40.13 & 33.27 & 28.04 & 31.57 \\
\hline Nordeste & \multicolumn{3}{|c|}{ Nivel de Pobreza } & Total \\
\hline \multicolumn{5}{|l|}{ Trabalho e Renda dos Moradores } \\
\hline Do Domicilio & 1 & $\mathrm{Pn}$ & $\mathrm{NP}$ & \\
\hline$\%$ de Domicilios com 0 Ocupados & 19.10 & 15.97 & 7.04 & 12.54 \\
\hline Pessoas por Ocupado no Domicilio & 4.22 & 2.87 & 2.28 & 2.84 \\
\hline \multicolumn{5}{|l|}{ Distribuiçăo dos Domicilios } \\
\hline \multicolumn{5}{|l|}{ Segundo o Tipo de Renda } \\
\hline So Renda de Trabalho & 61.58 & 52.36 & 48.26 & 52.55 \\
\hline S6 Outras Rendas (*) & 20.49 & 16.15 & 7.52 & 13.13 \\
\hline Renda de Trabalho e Outras Rendas & 17.93 & 31.49 & 44.22 & 34.32 \\
\hline \multicolumn{5}{|l|}{$\%$ de Pessoas $d 10$ anos e + } \\
\hline Desocupadas & 9.72 & 5.15 & 4.04 & 5.80 \\
\hline \multicolumn{5}{|l|}{$\%$ de Chefes com mais de 40 Anos } \\
\hline Aposentados ou Pensionistas & 30.04 & 49.36 & 43.57 & 42.35 \\
\hline
\end{tabular}

Aposentados ou Pensionistas

(") Aposentadoria, pensåo, abono permanencia, aluguel e outros.

FONTE: PNSN 1989.

NEPPIUNICAMP, 1998.

Dados referentes à renda e ao trabalho do conjunto dos moradores dos domicílios, podem agregar outras informações sobre o contraste da 
pobreza urbana das regiões Nordeste e Sudeste. A proporção de domicílios sem nenhuma pessoa ocupada é, nos dois níveis de pobreza, bem maior no Nordeste: como são menores as proporções de desempregados do que no Sudeste, pode-se inferir que são maiores as taxas de inatividade da região mais pobre. Também nela são maiores as proporções de domicílios que têm somente 'outras rendas' (aposentadoria, pensão, aluguéis, etc.) e não renda de trabalho. Note-se também que são bem maiores no Sudeste as porcentagens de domicílios que tanto têm renda de trabalho como renda de outra origem. Como já foi dito conseguir complementar, com renda do trabalho, as pequeníssimas 'outras rendas' de aposentadorias, pensões e aluguéis, parece ser o que faz toda a diferença entre a não pobreza e a pobreza não indigente ou a miséria.

De tudo isso, tanto das informações sobre o chefe do domicílio como do conjunto de moradores, vamos concluir que a principal diferença entre as duas regiões é a falta de oportunidades de trabalho num mercado urbano mais estruturado, mal compensada tal falta pelo exercício de toda sorte de expedientes e 'bicos', à guisa de trabalho por conta própria, e pelo ganho principalmente nos domicílios pobres não indigentes — de ínfimas aposentadorias e pensões e 'outras rendas'.

Neste contraste, a situação da região urbana do Norte e Centro-Oeste aproxima-se, amenizada, mais da do Nordeste urbano. A situação urbana da região Sul é mais contraditória. Essa região apresenta níveis relativamente baixos nas proporções totais de indigência e de pobreza não indigente (como também na relação da pobreza crônica ou estrutural com a mais recente), proporções e relação próximas às do Sudeste. Entretanto, em muitos dos traços da sua pobreza, quais sejam os relativos à falta de emprego e à falta de garantias, trabalhistas e previdenciárias do trabalho que os pobres do Sul urbano conseguem, eles parecem se aproximar mais da situação urbana nordestina. A situação dos seus aposentados pobres, no entanto, parece melhor, na medida que isto é indicado pela proporção mais alta de domicílios que auferem tanto renda do trabalho como 'outra' renda ${ }^{26}$.

${ }^{26}$ Vejam-se estatísticas como estas abaixo, tomando-se apenas os domicílios indigentes, para o Sul e para o Nordeste urbanos:

Número de pessoas por ocupado: 4,826 e 4,577; \% de domicílios com zero ocupados: 31,7 e 19,$1 ; \%$ de chefes empregados sem carteira do trabalho: 60,45 e 55.59; e \% de chefes conta-
Tabela 20

Trabalho e Renda dos Membros do Domicilio, Segundo Niveis de Pobreza, Grande Regiăo Trabalho e Renda
Urbana GRS,

\begin{tabular}{|c|c|c|c|c|}
\hline \multirow{2}{*}{$\begin{array}{l}\text { Sudeste } \\
\text { Trabalho e Renda dos Moradores } \\
\text { Do Domicilio }\end{array}$} & \multicolumn{3}{|c|}{ Nivel de Pobreza } & \multirow[t]{2}{*}{ Total } \\
\hline & $\mathrm{T}$ & $P n$ & NP & \\
\hline \% de Domiclios com 0 Ocupados & 10.22 & 6.49 & 6.99 & 7.13 \\
\hline Pessoas por Ocupado no Domicilio & 3.55 & 2.72 & 2.04 & 2.25 \\
\hline \multicolumn{5}{|l|}{ Distribuiçăo dos Domicilios } \\
\hline \multicolumn{5}{|l|}{ Segundo o Tipo de Renda } \\
\hline So Renda de Trabalho & 58.97 & 52.62 & 39.55 & 43.60 \\
\hline So Outras Rendas (") & 18.66 & 6.87 & 7.35 & 8.09 \\
\hline Renda de Trabalho e Outras Rendas & 22.38 & 40.51 & 53.10 & 48.31 \\
\hline \multicolumn{5}{|l|}{$\%$ de Pessoas $d 10$ anos e + } \\
\hline Desocupadas & 13.14 & 8.41 & 3.34 & 5.10 \\
\hline \multicolumn{5}{|l|}{$\%$ de Chefes com mais de 40 Anos } \\
\hline Aposentados ou Pensionistas & 34.11 & 32.05 & 45.10 & 42.04 \\
\hline Sul & \multicolumn{3}{|c|}{ Nivel de Pobreza } & Total \\
\hline \multirow{2}{*}{\multicolumn{5}{|c|}{ Trabalho e Renda dos Moradores }} \\
\hline & $T$ & $P_{n}$ & NP & \\
\hline$\%$ de Domiclilios com 0 Ocupados & 31.70 & 17.96 & 6.93 & 10.29 \\
\hline Pessoas por Ocupado no Domicilio & 4.83 & 2.99 & 2.01 & 2.24 \\
\hline \multicolumn{5}{|l|}{ Distribuiçâo dos Domicilios } \\
\hline \multicolumn{5}{|l|}{ Segundo o Tipo de Renda } \\
\hline So Renda de Trabalho & 38.52 & 33.45 & 33.61 & 33.91 \\
\hline So Outras Rendas (") & 32.71 & 18.36 & 7.09 & 10.54 \\
\hline Renda de Trabalho e Outras Rendas & 28.77 & 48.18 & 59.30 & 55.54 \\
\hline \multicolumn{5}{|l|}{$\%$ de Pessoas $d 10$ anos e +} \\
\hline Desocupadas & 12.93 & 7.63 & 3.12 & 4.50 \\
\hline \multicolumn{5}{|l|}{ \% de Chefes com mais de 40 Anos } \\
\hline Aposentados ou Pensionistas & 46.67 & 50.04 & 42.57 & 44.03 \\
\hline
\end{tabular}

guele outros.

FONTE: PNSN 1989.

NEPP/UNICAMP, 1998.

própria que não contribuem para a previdência (estimativa): 79,80 e 83,29. A estatística porém sobre a porcentagem de domicílios que têm tanto renda trabalho como 'outra' renda, coloca as populações urbanas indigentes do Sul em situação bem melhor do que as do Nordeste: os dados são 29,79 e 18,95 por cento, respectivamente. 